DOI: https://doi.org/10.34069/AI/2021.41.05.24

\title{
Humedal Bruselas de Florencia Caquetá como ecosistema estratégico de la región Surcolombiana
}

\author{
Brussels Wetland of Florencia Caquetá as a strategic ecosystem of the South Colombian \\ region
}

Received: November 2, 2020

\section{Resumen}

El objetivo de esta investigación fue caracterizar el humedal Bruselas ubicado en el municipio de Florencia Caquetá como ecosistema estratégico de la región Surcolombiana a partir de diversos criterios ecológicos y socioculturales de acuerdo a la metodología propuesta por Olaya y Sánchez (2013) del grupo de investigación Ecosistemas Surcolombianos (ECOSURC). El estudio permitió determinar que este humedal presenta características únicas que lo hacen merecedor de ser catalogado como zona de protección, así mismo debe ser definido como determinante ambiental e incluirlo en el Plan de ordenamiento territorial municipal de Florencia. El humedal Bruselas requiere con urgencia la implementación de una serie de acciones encaminadas a buscar su protección y conservación en razón a las múltiples problemáticas encontradas.

Palabras claves: Amazonia colombiana, ecosistema estratégico, efectos antrópicos, humedales, zona de protección.

\section{Introducción}

Los ecosistemas estratégicos se caracterizan por conservar el equilibrio natural relacionado con procesos ecológicos básicos como la regulación de climas, de agua, la depuración del aire, suelo y conservación de la biodiversidad. (Ministerio de Ambiente, 2021). Su importancia, además, está dada porque estos ecosistemas garantizan la
Accepted: April 12, 2021

Written by:

Magda Julissa Rojas-Bahamón ${ }^{84}$ https://orcid.org/0000-0003-4882-1476

Silvana G. Ruales Benavides ${ }^{85}$ https://orcid.org/0000-0003-2587-1470

Diego Felipe Arbeláez-Campillo ${ }^{86}$ https://orcid.org/0000-0002-9041-9563

\begin{abstract}
The objective of this research was to characterize the Brussels wetland located in the municipality of Florencia Caquetá as a strategic ecosystem of the South Colombian region based on various ecological and sociocultural criteria according to the methodology proposed by Olaya and Sánchez (2013) from the research group Surcolombianos Ecosistemas (ECOSURC). The study made it possible to determine that this wetland has unique characteristics that make it worthy of being classified as a protection zone, it must also be defined as an environmental determinant and included in the Municipal Land Use Plan of Florence. The Brussels wetland urgently requires the implementation of a series of actions aimed at seeking its protection and conservation due to the multiple problems encountered.
\end{abstract}

Keywords: Amazonia, strategic ecosystem, anthropic effects, wetlands, protection zone.

oferta de bienes y servicios ambientales para el desarrollo humano sostenible del país.

Sin embargo, a pesar de su importancia, su preservación está en crisis debido a dos factores fundamentales, la primera, porque no se realizan estudios de identificación de estos ecosistemas

\footnotetext{
${ }^{84}$ Doctora en Educación y Cultura Ambiental. Docente Secretaría de Educación de Florencia. Docente Universidad de la Amazonia. Grupo de Investigación Primmate. (Colombia).

${ }^{85}$ Bióloga. Universidad de la Amazonia. (Colombia).

${ }^{86}$ Magíster en Educación. Grupo de Investigación Primmate, Colciencias (Colombia).
} 
estratégicos a partir de criterios ecológicos y socioculturales, y el segundo, porque no existen políticas de preservación del ecosistema por la ausencia de estos estudios, situación que conlleva al desconocimiento de su importancia en un contexto local y regional.

En razón a lo anterior, este estudio cobra vital importancia pues el reconocimiento de los ecosistemas estratégicos permite valorar su necesidad en términos ecológicos y presentar argumentos y orientaciones que sirvan de base para promover su preservación a través de normativas locales y regionales.

De acuerdo con lo expuesto, el propósito de este estudio es caracterizar el humedal Bruselas, ubicado en la ciudad de Florencia departamento del Caquetá, caracterizarlo, identificar problemáticas y aplicar criterios que permitan determinar su importancia como ecosistema estratégico.

Adicionalmente, y en aras de presentar alternativas que mitiguen la problemática socio ambiental evidenciada en este ecosistema, se plantean propuestas de proyectos que pueden ser articuladas a un plan de manejo acorde a las necesidades de la comunidad con el fin de lograr la conservación y recuperación del humedal, pues, en concordancia con lo planteado por los Manuales Ramsar (2010), "El uso racional de los humedales es el mantenimiento de sus características ecológicas, lo cual se logra mediante la implementación de enfoques por ecosistemas, dentro del contexto del desarrollo sostenible". (p.17)

\section{Los humedales y su importancia como ecosistemas estratégicos}

Los humedales son zonas en las que el agua es el factor principal; se presentan en lugares donde el agua es poco profunda. Son considerados ecosistemas estratégicos por su alta diversidad y productividad biológica, pues contienen gran oferta de bienes y servicios ambientales y se comportan como filtros naturales de agua debido a las plantas que los conforman.

Según la Declaración de Changwon (2008) los humedales "proporcionan alimentos, almacenan el carbono, regulan el régimen hídrico, almacenan energía y son esenciales para la biodiversidad" (p.1). Sus beneficios y aportes a la humanidad son fundamentales para la preservación, pues son fuentes de agua, alimentos, biodiversidad, almacenamiento del carbono y medios de subsistencia.
Desde esta óptica, se considera relevante su conservación y uso racional, pues sus servicios ambientales son vitales para el bienestar humano. Las características singulares de los humedales conllevan a que la biodiversidad biológica que los habita desarrolle capacidad adaptativa y de supervivencia, dados los cambios extremos entre sequía e inundaciones de sus ciclos hidrológicos. En este sentido, la convención de Ramsar considera importante destacar el papel fundamental que tiene el entendimiento del funcionamiento hidrológico de los humedales, ya que "la existencia y disponibilidad de agua controlan los demás aspectos del ecosistema: productividad primaria, usos, hábitat y riesgo de degradación". (Ramsar, 2015, p.18).

Dentro del ciclo hidrológico, según el Ministerio del medio ambiente (2002, p.6), los humedales juegan un rol crítico en el mantenimiento de la calidad ambiental y regulación hídrica de las cuencas hidrográficas, estuarios y las aguas costeras, desarrollando, entre otras, funciones de mitigación de impactos por inundaciones, absorción de contaminantes, retención de sedimentos, recarga de acuíferos y proveyendo hábitats para animales y plantas, incluyendo un número representativo de especies amenazadas, endémicas y en vías de extinción.

Adicionalmente, se destaca su alta productividad porque pueden albergar diversas y numerosas especies de animales, de tal manera que muchas de las actividades humanas requieren de sus recursos naturales; entre estas actividades se pueden considerar la pesca, la agricultura, el pastoreo, el transporte, el turismo y la recreación.

\section{Problemáticas que amenazan los humedales}

Actualmente es preocupante la proyección a la baja de los servicios eco sistémicos, proporcionados por los humedales en nuestra sociedad, dado que se calcula que "la extensión mundial de los humedales disminuyó entre un 64 y un $71 \%$ en el siglo XX y que la pérdida y degradación de los humedales continúan en todo el mundo. Ramsar (2015, p.7).

En relación con lo expuesto, en la actualidad, una amenaza para los humedales es la alteración de los regímenes hídricos y la reclamación del espacio físico que estos ocupan, pues normalmente los propietarios de los predios aledaños no respetan los límites de los humedales y se las han arreglado para cambiar los niveles máximos de inundación. 
Según lo mencionado, en el informe de la Contraloría general de la República (2012) se encontró que, dadas las proyecciones, se esperaba que, en Colombia, "hasta el 2015 se alcanzaría tan sólo la delimitación del $44 \%$ de los humedales existentes en el país a escala 1:25.0008" (p.26), cifra que fue imposible de cumplir en relación con la meta que tenía esta entidad en el cuatrienio 2010-2014. Para los años posteriores, el mismo informe para la vigencia 2019-2020 señaló que "el inventario nacional de humedales está desactualizado, entre otros motivos, porque estos no se han delimitado, a pesar de que el Plan Nacional de Desarrollo 2010-2014 había fijado entre sus metas la delimitación del $100 \%$ a escala 1:25.000, no se logró avance alguno. Por tanto, no se tiene certeza sobre el número y extensión de los humedales del país" (Contraloría General de la Nación, 2020, p. 218).

Es de denotar que sobre este $44 \%$ de humedales, las Corporaciones Autónomas Regionales y de Desarrollo Sostenible (CAR-CDS) y autoridades ambientales urbanas, estaban comprometidas en la realización del proceso de zonificación, ordenamiento y determinación del régimen de usos de estos ecosistemas, los cuales según el Ministerio del medio ambiente (2002) "han sido afectados y en algunos casos destruidos por diferentes factores entre los que se encuentran una planificación y técnicas de manejo inadecuadas, y políticas de desarrollo sectorial inconsistente y desarticulado" (p. 6).
Aunado a lo anterior, entre las problemáticas de mayor repercusión, está la falta de conciencia social sobre el valor e importancia de los humedales, y el caso omiso de estas problemáticas en la planificación económica nacional; en consecuencia, los humedales y sus servicios ambientales están en peligro latente y para esto se demanda diseño, implementación, evaluación y seguimiento de estrategias de planificación y manejo de carácter integral.

\section{Legislación y plan de manejo ambiental para humedales}

Reconociéndose la importancia de los humedales como sistemas de conservación ambiental, se han creado herramientas y mecanismos jurídicos de protección con la finalidad de proteger estos ecosistemas, puesto que aunque son muy importantes para la preservación de la humanidad, se encuentran amenazados en todo el mundo.

En consecuencia, el marco jurídico y normativo, en materia de humedales, tiene como bases fundamentes los referentes legales presentados a continuación:

\section{Normatividad de orden internacional}

La normatividad a nivel internacional se detalla en la tabla No. 1.

Tabla 1.

Normatividad sobre humedales. Orden internacional. Fuente: autores.

\begin{tabular}{ll}
\hline La Convención de Ramsar de 1971 & $\begin{array}{l}\text { Es el primer tratado intergubernamental de cooperación internacional } \\
\text { sobre los humedales, que procura velar por la conservación y uso racional } \\
\text { de los recursos naturales de los humedales. }\end{array}$ \\
\hline $\begin{array}{l}\text { Convenio sobre diversidad biológica } \\
1992\end{array}$ & $\begin{array}{l}\text { Propende por la conservación, conocimiento y uso sostenible de la } \\
\text { biodiversidad, promueve la consolidación de sistemas nacionales de áreas } \\
\text { protegidas. }\end{array}$ \\
La Agenda 21 (Cumbre de Río, 92) & $\begin{array}{l}\text { Plantea como prioridad, los recursos de agua dulce, para la protección de } \\
\text { losistemas y la ordenación integrada de los recursos hídricos, y }\end{array}$ \\
\hline
\end{tabular}




\section{Normatividad de orden nacional}

La normatividad a nivel nacional se detalla en la tabla No. 2.

Tabla 2.

Normatividad sobre humedales. Orden nacional. Fuente: autores.

\begin{tabular}{|c|c|}
\hline $\begin{array}{l}\text { Constitución política de } \\
\text { Colombia } 1991\end{array}$ & $\begin{array}{l}\text { Establece: La obligación del estado y de los particulares de proteger las riquezas } \\
\text { naturales y culturales de la nación. }\end{array}$ \\
\hline Ley 99 de 1993 & $\begin{array}{l}\text { Crea el ministerio del medio ambiente y estructura el sistema nacional } \\
\text { ambiental SINA. }\end{array}$ \\
\hline Ley 165 de 1994 & $\begin{array}{l}\text { Aprueba el "Convenio sobre la Diversidad Biológica", para proteger los } \\
\text { ecosistemas y las especies. }\end{array}$ \\
\hline Ley 357 de 1997 & $\begin{array}{l}\text { Aprueba la convención Relativa a los Humedales de importancia Internacional, } \\
\text { especialmente como Hábitat de aves acuáticas. Impone obligaciones al Estado } \\
\text { colombiano para la conservación y protección de los humedales, considerados } \\
\text { en su acepción genérica. }\end{array}$ \\
\hline Política Nacional para & Estrategias para la conservación y uso racional de los humedales interiores de \\
\hline $\begin{array}{l}\text { Humedales Interiores en } \\
\text { Colombia del } 2001\end{array}$ & $\begin{array}{l}\text { Colombia con el fin de mantener y obtener beneficios ecológicos, económicos y } \\
\text { socioculturales, como parte integral del desarrollo del país }\end{array}$ \\
\hline Resolución 0157 de 2004. & $\begin{array}{l}\text { Se reglamentan el uso sostenible, conservación y manejo de los humedales y se } \\
\text { desarrollan aspectos referidos a los mismos en aplicación de la Convención } \\
\text { Ramsar. }\end{array}$ \\
\hline Resolución 196 de 2006 & $\begin{array}{l}\text { adopta la guía técnica para la formulación de planes de manejo para humedales } \\
\text { en Colombia }\end{array}$ \\
\hline \multirow[t]{4}{*}{ Ley 1333 de 2009} & Establece el procedimiento sancionatorio ambiental. \\
\hline & $\begin{array}{l}\text { Por el cual se dicta el código nacional de Recursos Naturales (Antiguo Decreto } \\
2811 \text { de 1974) }\end{array}$ \\
\hline & $\begin{array}{l}\text { Se reglamenta parcialmente el Título I de la ley } 9 \text { de } 1979 \text { en cuanto a usos del } \\
\text { agua y residuos líquidos (Antiguo Decreto } 1594 \text { de 1984) }\end{array}$ \\
\hline & Por el cual se designan unos humedales para ser incluidos en la lista de \\
\hline Decreto Único Reglamentario & Humedales de Importancia Internacional, en cumplimiento de lo dispuesto en la \\
\hline \multirow[t]{2}{*}{1076 de 2015} & $\begin{array}{l}\text { Ley } 357 \text { de } 1997 \text {. El manejo de estos humedales de Importancia Internacional se } \\
\text { regirá de acuerdo con los lineamientos y directrices emanados por la }\end{array}$ \\
\hline & $\begin{array}{l}\text { Convención Ramsar, la Política Nacional de Humedales Interiores, Política para } \\
\text { el Manejo Integrado de las Zonas Costeras, así como por la normatividad que } \\
\text { expida el Ministerio del Medio Ambiente para estas áreas (Antiguo Decreto } \\
1667 \text { de 2002) }\end{array}$ \\
\hline
\end{tabular}

\section{Normatividad de orden Regional}

En el ámbito regional se hallaron dos acuerdos municipales orientados a la conservación de los

Tabla 3.

Normatividad sobre humedales. Orden municipal. Fuente: autores.

Se adopta el plan de Desarrollo Participativo y comunitario 2004-2007 y se

Acuerdo Municipal de 2004 aprueban dentro del presupuesto participativo una partida para el mantenimiento de los humedales de la ciudad. humedales en la ciudad de Florencia. Los acuerdos se resumen en la tabla No. 3 .

Plan de desarrollo municipal de Florencia (2008-2011), establece en uno sus subprogramas, "la conservación de ecosistemas estratégicos: formulación del plan de ordenamiento y manejo ambiental de los humedales del municipio de Florencia; determinación de espacios públicos para la recuperación de los humedales".

En ese mismo orden de ideas, es importante considerar que, en concordancia por lo dispuesto por las Corporaciones Autónomas Regionales, existen determinantes ambientales relacionados con la importancia de los humedales como ecosistemas estratégicos. El marco normativo se resume como sigue: 
Tabla 4.

Determinantes ambientales relacionados con la importancia de los humedales como ecosistemas estratégicos Fuente: Corpoamazonia (2014)

\begin{tabular}{|c|c|c|c|}
\hline \multicolumn{2}{|c|}{$\begin{array}{l}\text { Determinante de competencia de la CAR de acuerdo con } \\
\text { el marco normativo }\end{array}$} & $\begin{array}{l}\text { Marco normativo que } \\
\text { la establece como } \\
\text { determinante }\end{array}$ & $\begin{array}{l}\text { Marco normativo } \\
\text { que desarrolla } \\
\text { determinante y/o le } \\
\text { da contenido }\end{array}$ \\
\hline $\begin{array}{l}\text { Areas de especial } \\
\text { importancia } \\
\text { ecosistémica o } \\
\text { ecológica }\end{array}$ & $\begin{array}{l}\text { Páramos y subpáramos } \\
\text { Nacimientos de agua } \\
\text { Zonas de recarga de acuíferos } \\
\text { Rondas hidráulicas de los cuerpos } \\
\text { de agua } \\
\text { Humedales } \\
\text { Pantanos } \\
\text { Lagos } \\
\text { Lagunas } \\
\text { Ciénagas } \\
\text { Manglares } \\
\text { Reservas de flora y fauna } \\
\text { Humedales RAMSAR }\end{array}$ & $\begin{array}{l}\text { - Literal a, Numeral 1, } \\
\text { Artículo } 10 \text { de la Ley } 388 \\
\text { de } 1997 \\
\text { - Numeral 1, artículo } 4 \\
\text { del Decreto } 3600 \text { de } 2007 \\
\text { - Numeral } 1 \text { Artículo } 7 \\
\text { del Decreto } 3600 \text { de } 2007 \\
\text { - Decreto } 2372 \text { de } 2010 \\
\text { - Artículo } 23 \text { Decreto } \\
1640 \text { de } 2012\end{array}$ & $\begin{array}{l}\text { - Decreto } 1541 \text { de } \\
1978 \\
\text { - Ley } 357 \text { de } 1997 \\
\text { - Ley } 373 \text { de } 1997 \\
\text { art. } 10 \\
\text { - Artículos } 2 \text { y } 8 \\
\text { Resolución } 769 \text { de } \\
2002 \\
\text { - Resolución } 157 \text { de } \\
2004 \\
\text { - Resolución } 196 \text { de } \\
2006 \\
\text { - Artículo } 2 \text { de la Ley } \\
\text { 1523 de 2012 }\end{array}$ \\
\hline $\begin{array}{l}\text { Elementos naturales y } \\
\text { normas técnicas para } \\
\text { la conservación, } \\
\text { preservación y } \\
\text { recuperación de los } \\
\text { elementos naturales } \\
\text { del espacio público }\end{array}$ & $\begin{array}{l}\text { Áreas para la conservación y } \\
\text { preservación del sistema orográfico } \\
\text { o de montañas, tales como: cerros, } \\
\text { montañas, colinas, volcanes y } \\
\text { nevados } \\
\text { Áreas para la conservación y } \\
\text { preservación del sistema hídrico: } \\
\text { conformado por: } \\
\text { a) elementos naturales relacionados } \\
\text { con corrientes de agua tales como: } \\
\text { cuencas y microcuencas, } \\
\text { manantiales, ríos, quebradas, } \\
\text { arroyos, playas fluviales, rondas } \\
\text { hídricas, zonas de manejo, zonas de } \\
\text { bajamar y protección ambiental, y } \\
\text { relacionados con cuerpos de agua, } \\
\text { tales como mares, playas marinas, } \\
\text { arenas y corales, ciénagas, lagos, } \\
\text { lagunas, pantanos, humedales, } \\
\text { rondas hídricas, zonas de manejo y } \\
\text { protección ambiental; } \\
\text { b) Elementos artificiales o } \\
\text { construidos, relacionados con } \\
\text { corrientes de agua, tales como: } \\
\text { canales de desagüe, alcantarillas, } \\
\text { aliviaderos, diques, presas, represas, } \\
\text { rondas hídricas, zonas de manejo y } \\
\text { protección ambiental, y } \\
\text { relacionados con cuerpos de agua } \\
\text { tales como: embalses, lagos, } \\
\text { muelles, puertos, tajamares, } \\
\text { rompeolas, escolleras, rondas } \\
\text { hídricas, zonas de manejo y } \\
\text { protección ambiental; } \\
\text { Áreas de especial interés ambiental, } \\
\text { científico y paisajístico, tales como: } \\
\text { i) Parques naturales del nivel } \\
\text { nacional, regional, departamental y } \\
\text { municipal; y } \\
\text { ii) Áreas de reserva natural, } \\
\text { santuarios de fauna y flora. }\end{array}$ & $\begin{array}{l}\text { - Literal a, Numeral 1, } \\
\text { Artículo } 10 \text { de la Ley } 388 \\
\text { de } 1997 \\
\text { - Numeral 1, artículo } 4 \\
\text { del Decreto } 3600 \text { de } \\
2007 \\
\text { - Numeral } 1 \text { Artículo } 7 \\
\text { del Decreto } 3600 \text { de } 2007 \\
\text { - Artículos 2, } 5 \text { y } 17 \text { del } \\
\text { Decreto } 1504 \text { de } 1998 \\
\text { - Decreto } 2372 \text { de } 2010 \text { - } \\
\text { Artículo } 5 \text { Decreto } 1120 \\
\text { de } 2013\end{array}$ & $\begin{array}{l}\text { - Numerales 5, } 16 \text { y } \\
18 \text { artículo 31Ley } 99 \\
\text { de } 1993 \\
\text { - Decreto } 1640 \text { de } \\
2012 \\
\text { - Decreto } 2372 \text { de } \\
2010 \\
\text { - Decreto } 1120 \text { de } \\
2013\end{array}$ \\
\hline
\end{tabular}




\section{AMAZONDA \\ Irvegtiga}

Teniendo en cuenta que la conservación y uso sustentable de los humedales, se vuelve impostergable que los humedales deben manejarse de manera Integral como un ecosistemas con criterio social, por lo tanto se considera relevante la presentación de los aportes básicos para la elaboración de un plan de manejo, el cual según la resolución 196 de 2006, se define como un documento de carácter técnico, que una vez formulado por la autoridad ambiental competente y aprobado por la Dirección de Ecosistemas del Ministerio de Ambiente y Desarrollo Sostenible, será adoptado por la autoridad ambiental mediante acto administrativo.

Tipificación e inventario de humedales en el municipio de Florencia

Los estudios realizados sobre humedales en el municipio de Florencia Caquetá son muy limitados y la información es bastante incipiente.

En el ámbito local, solo se registra información de 11 humedales en el documento denominado "Inventario y caracterización de los humedales urbanos del municipio de Florencia" (Vergel, Losada y Montoya, 2009). El estudio establece localización, tipo de humedal, cobertura vegetal, uso de suelo, importancia, problemática ambiental, así como algunos registros fotográficos.

Otro referente que se encontró respecto a identificación de humedales, fue un mapa elaborado en el marco del estudio denominado "Caracterización biofísica o socioeconómica del

Tabla 5.

Humedales en el municipio de Florencia Caquetá. área de influencia del Cerro de Miraflores y sensibilización ambiental respecto al Páramo en el departamento del Caquetá" en el que se presenta un plano a escala 1:100.000 que incluye un cuadro con 18 humedales de Florencia, con sus nombres y área. (Corpoamazonia, 2014), sin embargo, no se establece en el documento, la información respecto a la caracterización de los mencionados humedales.

Se referencian así mismo, documentos resultados de consultorías realizadas por Corpoamazonia y algunas entidades privadas prestadoras de servicios ambientales orientadas hacia la formulación de planes de manejo ambiental para el humedal Versalles, Calle Oscura, El Bosque, Esmeralda y el San Luis (Bravo, Rubiano, Castro, Luna, Torres y Rincón, 2009)

A nivel nacional, respecto a la caracterización de humedales en Florencia, el Ministerio de Ambiente y desarrollo sostenible. Dirección de bosques, biodiversidad y servicios ecosistémicos - Grupo de humedales (2014), presentó un informe de humedales del departamento del Caquetá que involucra 19 humedales para el municipio de Florencia. El informe describe en una tabla de datos la localización, tipo, descripción general y problemática, sin embargo, la información se presenta de una manera muy general.

De esta manera, con la información anterior se puede establecer que oficialmente se encuentran identificados y tipificados 19 humedales en el municipio de Florencia, así:

\begin{tabular}{|c|c|c|}
\hline \multirow{2}{*}{ No. } & \multicolumn{2}{|c|}{ HUMEDALES EN FLORENCIA CAQUETÁ } \\
\hline & TIPO & NOMBRE \\
\hline 1. & Madre vieja/Meandro & Aeropuerto \\
\hline 2. & Madre Vieja & San Luis \\
\hline 3 . & Madre vieja & Puerto Arango \\
\hline 4. & Cananguchal & Vereda el Venado \\
\hline 5. & Bosque inundable & Centro Macagual \\
\hline 6. & Bosque inundable & Quebrada La Turbia \\
\hline 7. & Quebrada & La Perdiz \\
\hline 8. & Laguna & El Carmen \\
\hline 9. & Cananguchal & Vereda La Hacienda \\
\hline 10. & Humedal & La Castilla \\
\hline 11. & Humedal & La esmeralda \\
\hline 12. & Humedal & El bosque \\
\hline 13. & Humedal & Londres \\
\hline 14. & Humedal & Calle Oscura \\
\hline 15. & Humedal & Azola Anabaena \\
\hline 16. & Humedal & El Puerto \\
\hline 17. & Humedal & Versalles \\
\hline 18. & Humedal & Fuente de Agua \\
\hline 19. & Humedal & Siglo XXI \\
\hline
\end{tabular}


Sin embargo, se estima que en territorio del municipio de Florencia de $2200 \mathrm{~km}^{2}$ y de gran influencia hídrica, se pueden registrar más humedales de los que oficialmente reportan los estudios y los informes técnicos mencionados anteriormente.

De manera particular, respecto al humedal Bruselas objeto del presente estudio, no se encuentran registros en los documentos oficiales del municipio de Florencia, ni de la corporación autónoma regional (CORPOAMAZONIA), razón por la cual no cuenta con información respecto a su localización, tipificación y problemáticas inherentes a él.

Cabe aclarar que, en el contexto de la planificación y ordenamiento ambiental territorial, ninguno de los humedales incluyendo el humedal Bruselas se encuentra incorporado en el POT vigente (año 2000) como suelo de protección, ni se reconocen como parte de la estructura ecológica del municipio. Lo cual se refleja en las múltiples problemáticas por conflicto de uso del suelo dentro de las que se destacan asentamientos subnormales, parcelaciones ilegales, extracción de recursos, actividades agropecuarias, entre otras.

\section{Metodología}

\section{Diseño}

El estudio involucró las siguientes etapas:

1) Revisión documental respecto a humedales con base en el contexto internacional, nacional y regional.

2) Realización de trabajo de campo consistente en visita del humedal para identificación, localización geográfica, recorrido y observación paisajística de flora y fauna. En esta fase se aplicó la ficha técnica de levantamiento de datos de humedales propuesta en la metodología estandarizada para la evaluación de humedales (CONACyTCONAGUA, 2015).

3) Reconocimiento, jerarquización y descripción del humedal con base en los criterios de ecosistemas estratégicos propuestos por Olaya y Sánchez (2013).

4) Identificación de problemáticas del humedal con relación a cada criterio y los resultados de las entrevistas realizadas a los pobladores de la zona.

5) Planteamiento de proyectos para involucrarlos a un plan de manejo ambiental para el humedal Bruselas, con base en problemáticas identificadas.

\section{Ficha técnica de levantamiento de datos}

La ficha técnica está compuesta con información sobre las variables que son necesarias para caracterizar, delimitar y clasificar los humedales a nivel de sitio, escala 1:20,000. El levantamiento de datos en el sitio, consta de dos partes: la que integra datos trabajados previo a los trabajos de campo, básicamente información de la literatura e interpretación de imágenes y cartografía, y la que comprende la información levantada en campo.

El trabajo, cuyos resultados se inscriben en la ficha técnica, está orientado a generar y analizar información para determinar: a) las generalidades del humedal. Esta información se refiere básicamente a la ubicación del humedal tanto a nivel de cuenca como de ubicación municipal en el que se encuentra. b) La delineación. Esta es la información sobre la extensión del humedal que se determina mediante la información cartográfica de la periferia o borde del humedal. La información se genera mediante cartografía. c) La caracterización del humedal. Esta información se refiere a los cuatro criterios distintivos del ecosistema, tomando como base parámetros de calidad del agua, vegetación hidrófila, suelos hidromórficos y aspectos socioeconómicos y de manejo. Para la indagación de los aspectos socioecómicos y de manejo se aplicaron entrevistas semiestructuradas a los pobladores de la zona. Las variaciones de los tres primeros parámetros, determinan el tipo de humedal y por tanto su clasificación.

\section{Resultados}

En primer lugar, se aclara que en razón a que el humedal identificado en el presente estudio, no se encuentra en los documentos oficiales, se le denominará "Bruselas" por su localización geográfica cercana al barrio del mismo nombre.

\section{Localización y caracterización del humedal Bruselas}

El humedal Bruselas se encuentra localizado en el barrio Bruselas en la comuna sur-este de la ciudad de Florencia departamento del Caquetá a 259 msnm. Cuenta con una extensión aproximada de $2.905 \mathrm{~m} 2$ y según tipificación de humedales de Ricaurte, L.F., Núñez-Avellaneda, M., Marín, C.A., Velásquez-Valencia, A., Pinilla, M.C., Betancourt, B. Salazar,

C. Mojica, J. I. (2014), corresponde a la clase de lagos lenticos permanentemente inundados con cobertura herbácea - arbustiva, representada por una estructura vegetativa asociada a un dosel abierto con una altura máxima de $4 \mathrm{~m}$ y por un sotobosque disperso. 


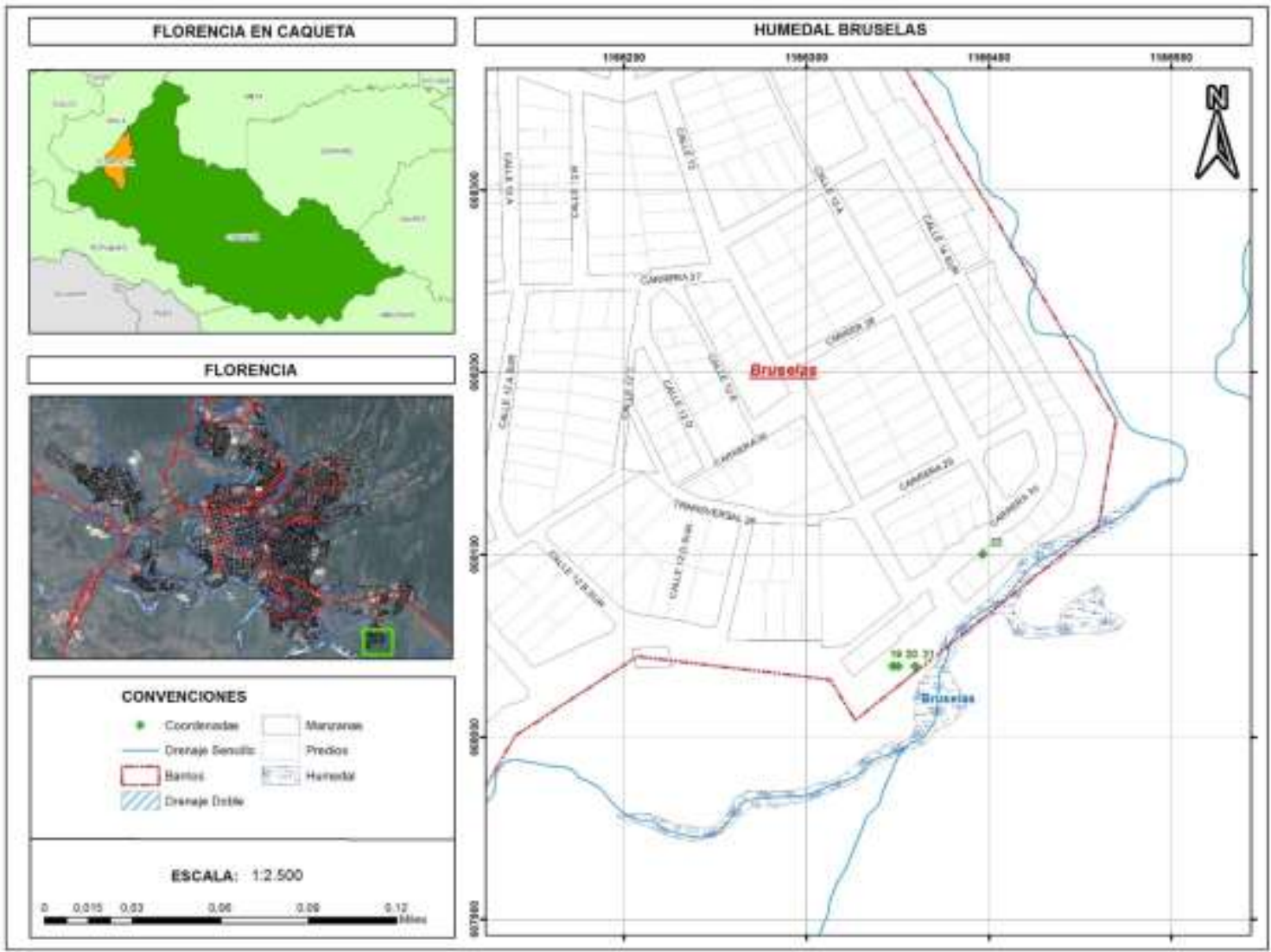

Mapa 1. Localización humedal Bruselas. Fuente: autores.

El humedal recibe aguas del Río Hacha. Es un humedal continental tipo lago de agua dulce, clima tropical, con una temperatura ambiental de $25^{\circ} \mathrm{C}$ y $23.8^{\circ} \mathrm{C}$ para el suelo. Se caracteriza por poseer un relieve de llanura ubicado en una cuenca con una pendiente entre 0 y $5 \%$ y presenta un tipo de erosión física debido a la compactación e inundación.

Respecto a las características edafológicas, se pudo observar que existe presencia de drenaje con un flujo lento superior a $0.3 \mathrm{~m} / \mathrm{s}$. Se constató que la periodicidad de inundación es estacional; respecto al suelo, se determinó el tipo en la parte externa del humedal el cual corresponde a arcillas y material orgánico.

\section{Vegetación}

En relación a las características biológicas, la cubierta del humedal presenta aproximadamente un $60 \%$ de vegetación, un $20 \%$ de hojarasca y un $20 \%$ de espejo de agua. Se evidenció, por la fecha en que se realizó el proceso de observación y muestreo que existe colmatación del humedal, debido a la temporada de sequía. Por esta razón, se observó presencia de vegetación en las orillas y sobre el humedal, formando manchones. La vegetación aledaña al humedal corresponde a bosque de galería, vegetación de matorral y pastizales. Así mismo, se observó comunidades vegetales de tipo arbóreo y arbustivo. Se registró la presencia de lechuga de agua (Pistia stratiotes), pasto estrella africano (Cynodon plectostachyus), árbol de yarumo (Cecropia peltata), Cananguchal (Mauritia flexuosa), Platanillo (Heliconia hirsuta), juncos (Schoenoplectus californicus), arazá (Eugenia stipitata), cordoncillo (Piper aduncum), guayabo y gran variedad de especies acuáticas. 

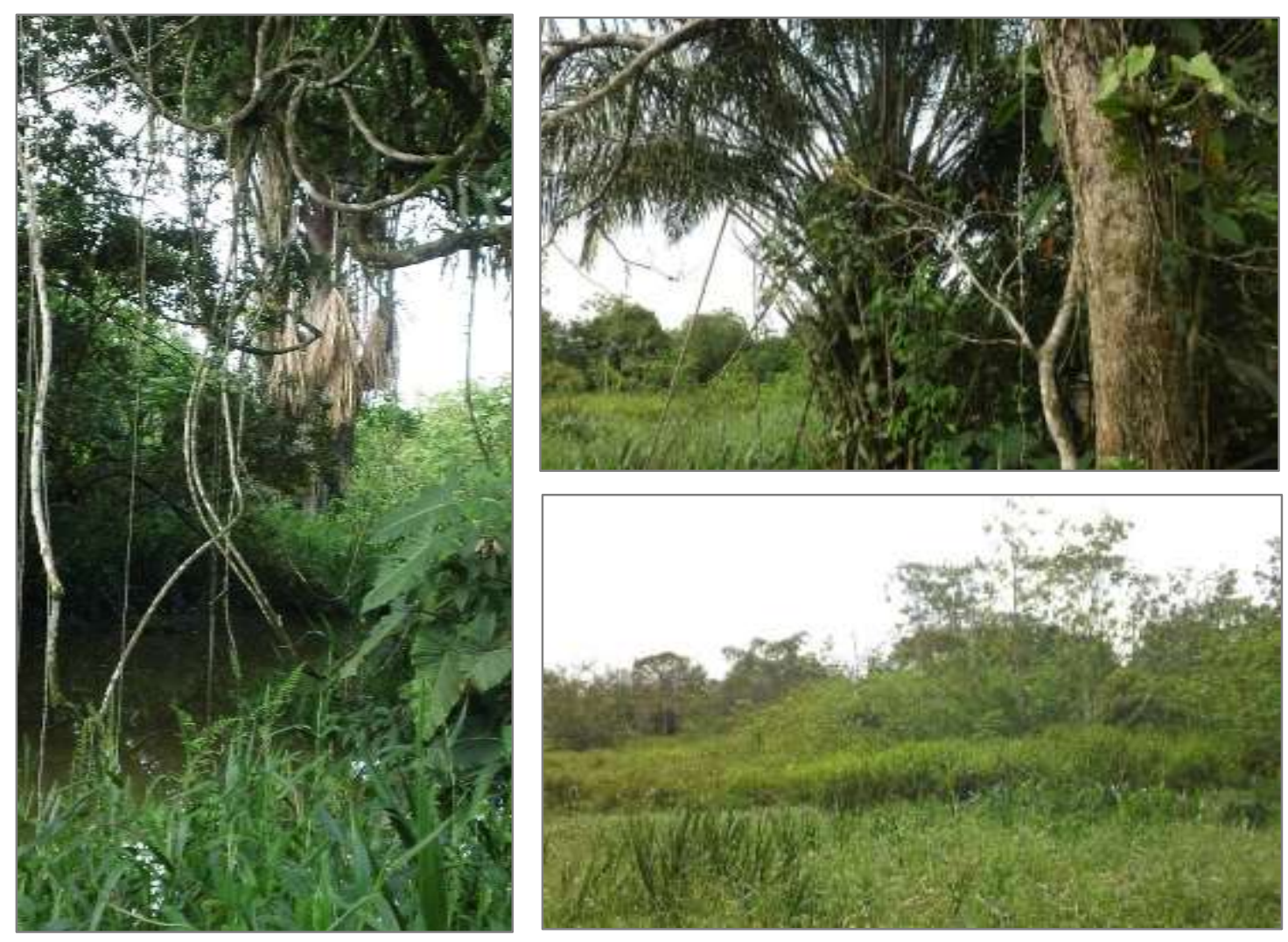

Figura 1. Registro fotográfico vegetación humedal Bruselas. Bosque de galería, vegetación de matorral y pastizales. Fuente: Autores.

\section{Fauna}

En cuanto a fauna, se pudo realizar avistamiento de especies de aves como el Pisingo (Dendrocygna viduat), el loro comejenero (Forpus conspicillatus), el chamón (Crotophaga ani), el arrendajo (Psarocolius decamanus), la garza blanca (Ardea alba), la pava hedionda (Opisthocomus hoazín), la guacharaca (Ortalis ruficauda), el loro coroniamarillo (Amazona ochrocephala), la garza negra aninga (Anhinga anhinga) y aves migratorias de gran importancia ecológica.

Se registró igualmente la presencia de babillas (Caimán crocodylus), charapas (podocnemis expansa), chuchas (Didelphis marsupialis), ardillas (Sciurus $s p$ ) y lagartijas de la familia Iguanidae, Teiidae, Gekkonidae y Dactyloidae. Así mismo, los pobladores informaron de la presencia de especies como Morrocoy (Chelonoidis carbonaria), Chiguiros (Hydrochoerus hydrochaeris), güios (Boa constrictor), Serpientes corales (Micrurus sp.) y serpientes X (Bothrops atrox).

Cabe destacar que se encontró caracol africano (Achatina fullica), especie invasora cuya amenaza se concentra en que desplaza a otras especies, destruye ecosistemas y es portadora de bacterias y parásitos peligrosos que atentan contra la salud humana y animal. 

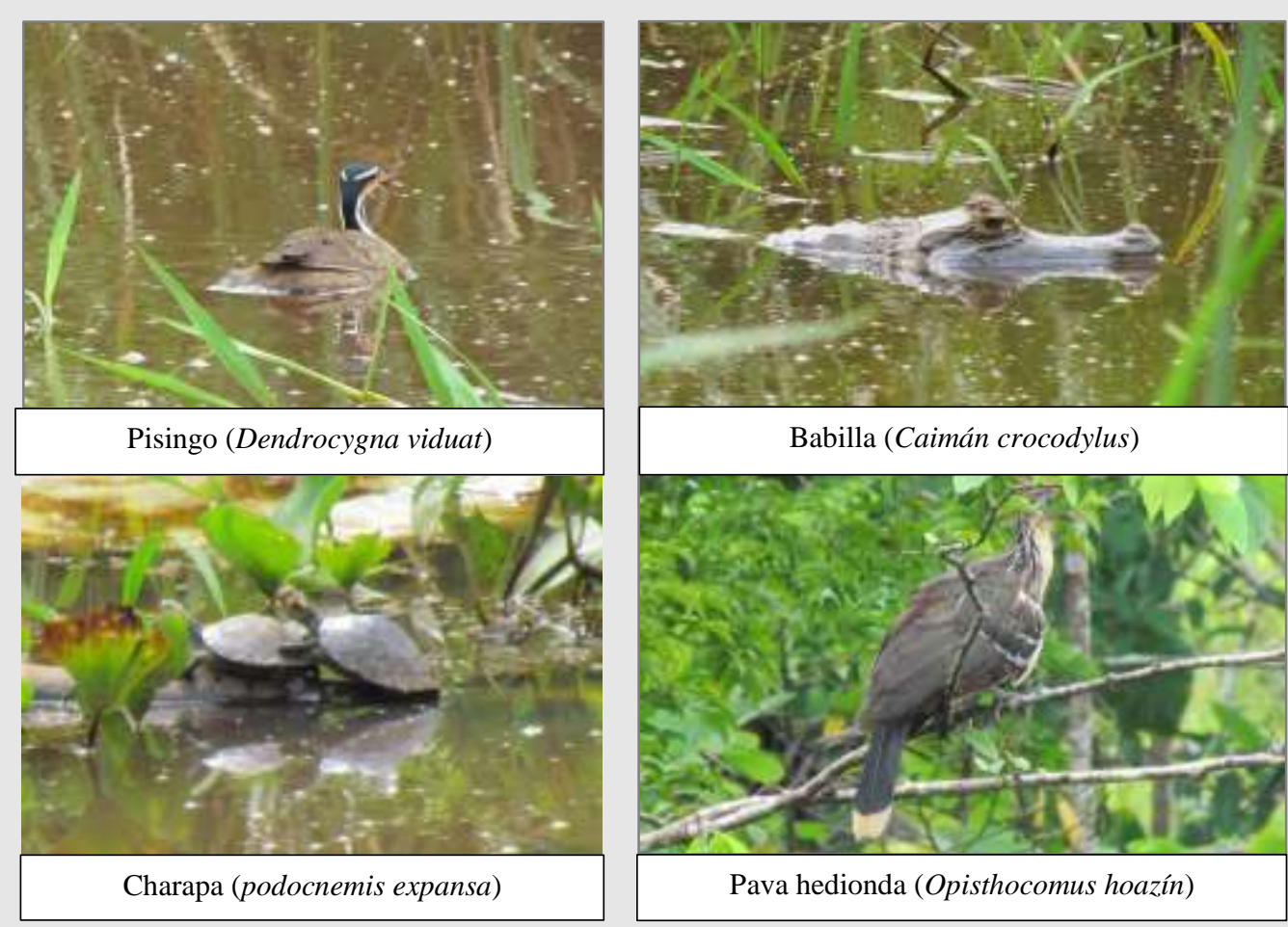

Figura 2. Registro fotográfico fauna humedal Bruselas.

Fuente: Jonathan Gutiérrez. Biólogo. Magíster Ciencias Biológicas.

\section{Problemáticas del humedal Bruselas}

El proceso de observación en terreno, así como el análisis de las entrevistas realizadas a pobladores, permitió evidenciar las problemáticas presentadas sobre el humedal Bruselas. De esta manera, se encontraron actividades de tipo urbano representados en asentamientos subnormales. Se evidenció un importante impacto antrópico a nivel paisajístico dado que se encontró afectación de la vegetación por construcciones de viviendas y cercas que generan ocupación del cauce y de la ronda hídrica del humedal.

En el área circundante del humedal se detectaron actividades agrícolas, representadas en siembra de caña de azúcar y plátano principalmente.
Igualmente se determinaron otras actividades productivas como crianza de aves de corral. Se encontró igualmente alta contaminación por estancamiento, debido a vertimientos de aguas residuales doméstica y hospitalaria, en este último, por la presencia de una clínica psiquiátrica en el sector.

Los testimonios de pobladores permitieron determinar actividades que atentan contra la diversidad natural del ecosistema, como son la caza de fauna silvestre (aves, chigüiros), sacrificio de animales considerados peligrosos para el asentamiento (serpientes, babillas) y actividades de crianza de cerdos sobre la ronda hídrica, que arrojaban sus desperdicios directamente sobre las aguas del humedal. 


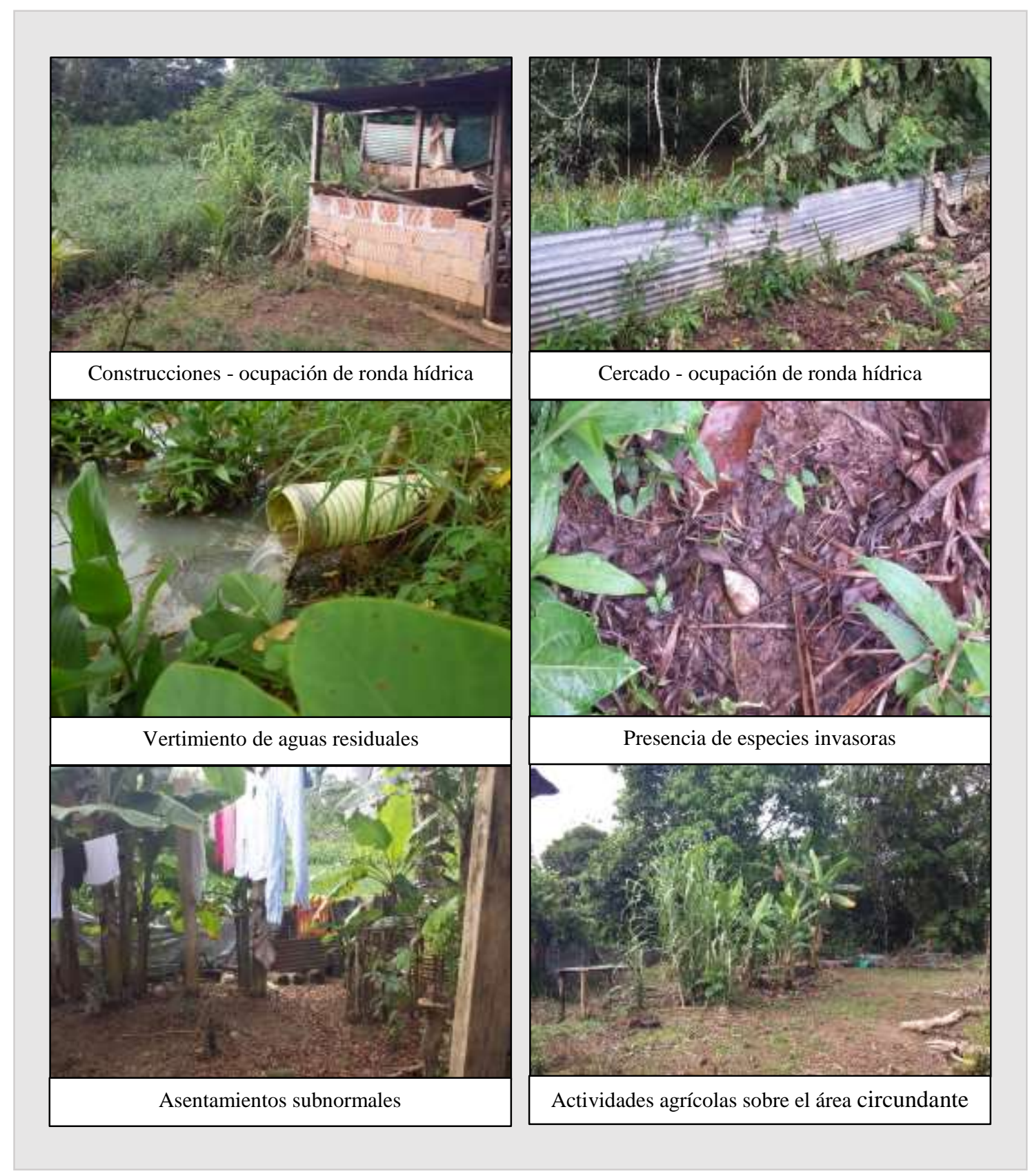

Figura 3. Registro fotográfico problemáticas del Humedal Bruselas. Fuente: autores.

\section{Criterios para considerar El Humedal Bruselas como Un Ecosistema Estratégico}

De acuerdo a los procesos de observación en campo y con base en lo postulado por Olaya y
Sánchez (2013), se identificaron y jerarquizaron los siguientes criterios que determinan que el humedal Bruselas puede considerarse un ecosistema estratégico: 
Tabla 6.

Criterios que determinan el Humedal Bruselas como ecosistema estratégico.

\begin{tabular}{|c|c|}
\hline Criterio & Descripción \\
\hline Defensas y amenazas naturales (C18) & $\begin{array}{l}\text { El ecosistema tiene la capacidad de generar, dinamizar o regular } \\
\text { fenómenos naturales que afectan de manera negativa, tanto } \\
\text { sistemas naturales como sentamientos humanos, infraestructura y } \\
\text { servicios públicos o privados. La amenaza natural asociado al } \\
\text { humedal es la de inundación y la generación de enfermedades } \\
\text { tropicales a los habitantes cercanos debido a la presencia de } \\
\text { mosquitos. }\end{array}$ \\
\hline Oferta hídrica (C26) & $\begin{array}{l}\text { El ecosistema posee una oferta hídrica significativa de espejo de } \\
\text { agua. }\end{array}$ \\
\hline Interacciones entre ecosistemas (C25). & $\begin{array}{l}\text { El humedal Bruselas establece corredor biológico a través de la } \\
\text { corriente de agua del río Hacha, un ecosistema importante de la } \\
\text { región a través del cual se establecen relaciones naturales de } \\
\text { suministro, flujo e intercambio de materiales, energía y especies. } \\
\text { Por ende, el ecosistema es necesario para mantener procesos } \\
\text { relacionados con el flujo genético, la migración de animales } \\
\text { silvestres o recursos hidrobiológicos y la conservación de los } \\
\text { corredores biológicos. }\end{array}$ \\
\hline Depuración natural de aguas (C9). & $\begin{array}{l}\text { El ecosistema merece tener un manejo especial, dado que cumple } \\
\text { la función de recibir, evacuar y depurar aguas con residuos sólidos } \\
\text { y líquidos de origen doméstico, agropecuario e industrial. Se } \\
\text { requiere un manejo correctivo, pues se detectó que el humedal } \\
\text { recibe aguas residuales del barrio aledaño. }\end{array}$ \\
\hline Diversidad natural (C23). & $\begin{array}{l}\text { El ecosistema es importante para perpetuar la biodiversidad animal } \\
\text { y vegetal en esta zona, especies y otros recursos bióticos, acuáticos } \\
\text { y terrestres que hacen parte del patrimonio natural de la región. }\end{array}$ \\
\hline $\begin{array}{l}\text { Paisaje y creación artística y literaria } \\
\text { (C2) }\end{array}$ & $\begin{array}{l}\text { El ecosistema posee paisajes naturales y culturales que constituyen } \\
\text { recursos de valor estético o de interés para moradores y visitantes, } \\
\text { en actividades como avistamiento de aves y otros animales. }\end{array}$ \\
\hline Actividades Educativas y científicas (C13). & $\begin{array}{l}\text { El ecosistema es importante para realizar actividades científicas y } \\
\text { educativas, tales como: prácticas de campo, excursiones, trabajos } \\
\text { de grado y proyectos de investigación, tanto de las ciencias } \\
\text { naturales como de las ciencias sociales. Presenta una riqueza } \\
\text { enorme en términos biológicos y sociales que ameritan procesos de } \\
\text { investigación. }\end{array}$ \\
\hline $\begin{array}{l}\text { Reconocimiento legal y académico } \\
\text { (C11). }\end{array}$ & $\begin{array}{l}\text { El humedal Bruselas se puede reconocer como un Área de Manejo } \\
\text { Especial (Área Forestal Protectora o Santuario de Fauna) una } \\
\text { Reserva Natural de la Sociedad Civil o un componente del } \\
\text { Patrimonio Natural o Cultural. Se requiere con urgencia } \\
\text { disposiciones legales o propuestas académicas o investigativas } \\
\text { para su protección }\end{array}$ \\
\hline
\end{tabular}

La identificación de los anteriores criterios permitió catalogar las amenazas más comunes para cada criterio. Además, se identificaron problemáticas asociadas a estas amenazas. 


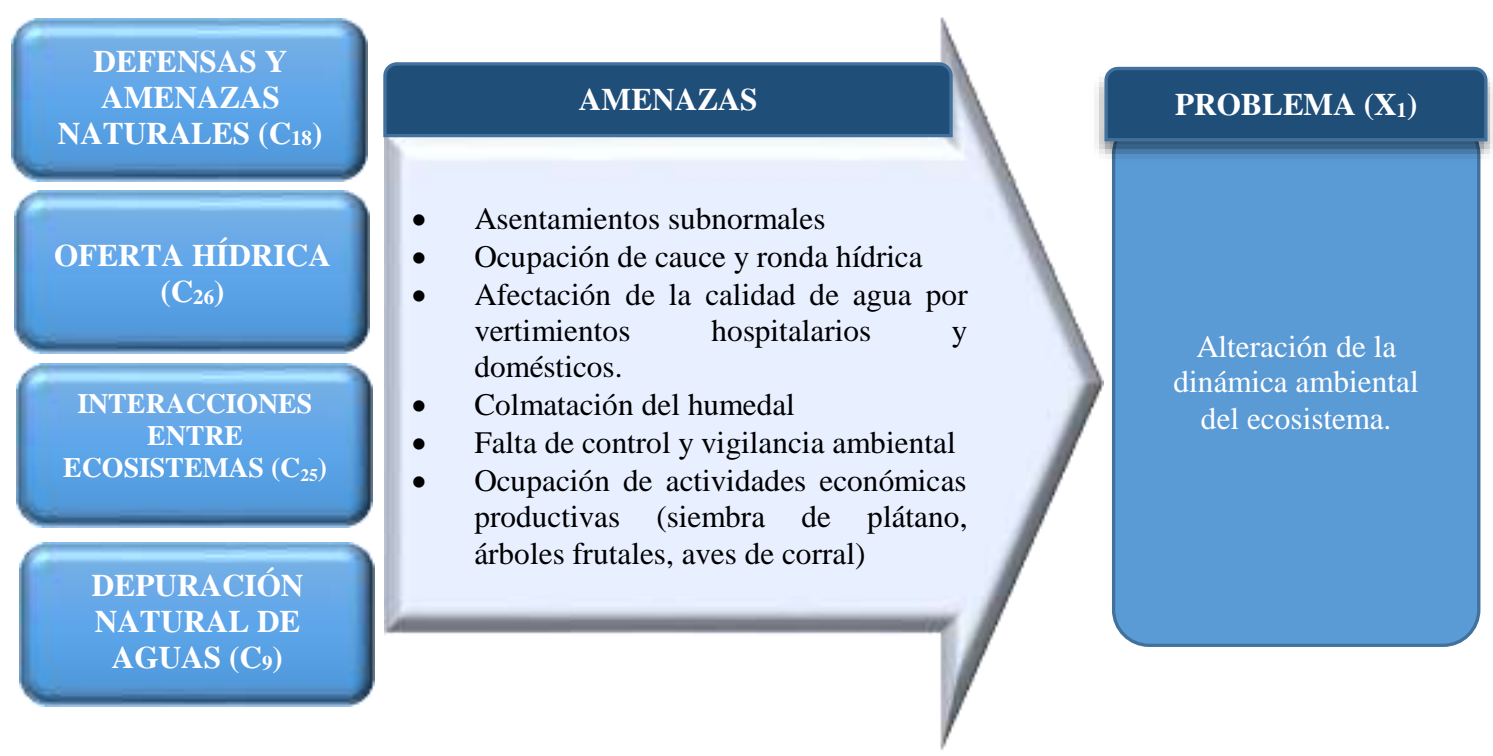

Figura 4. Identificación de amenazas comunes. Problema: dinámica ambiental. Fuente: autores.

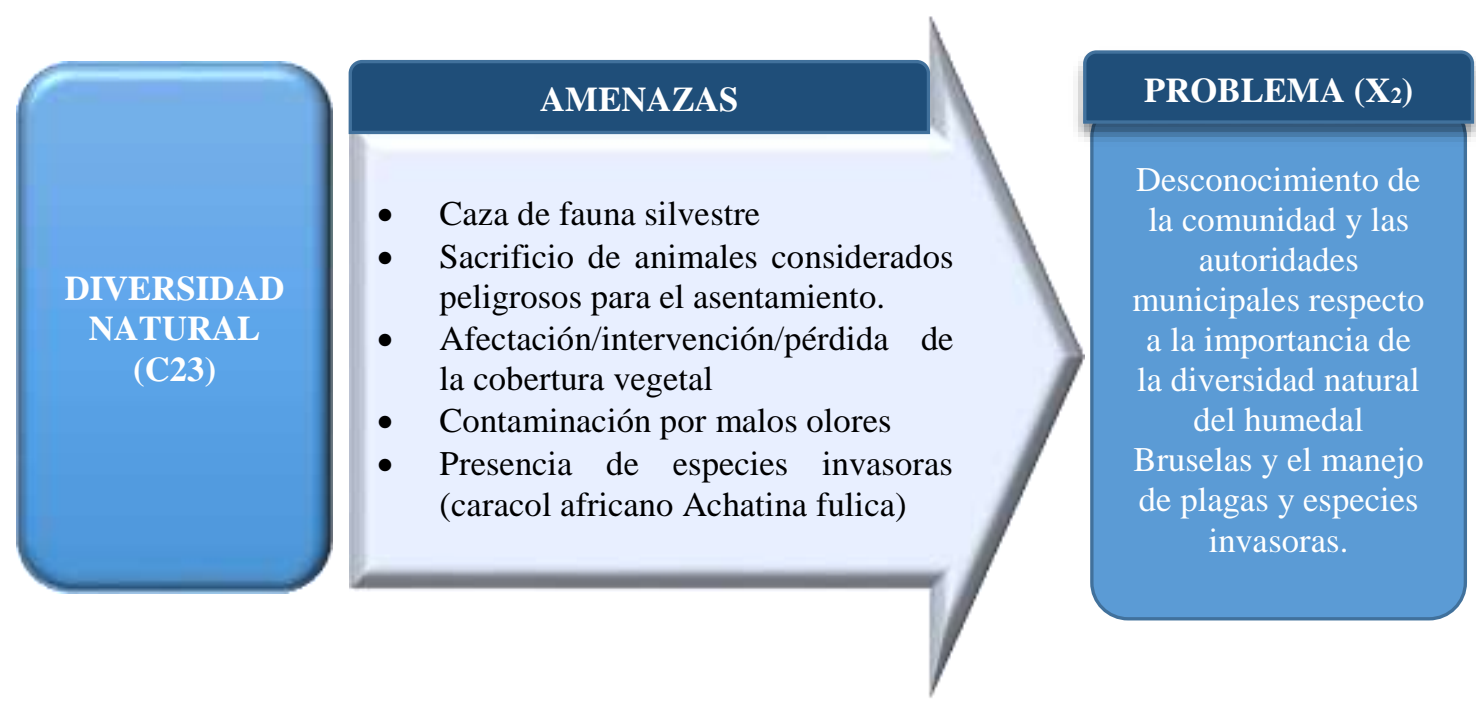

Figura 5. Identificación de amenazas y problemas para el criterio diversidad natural. Fuente: autores.
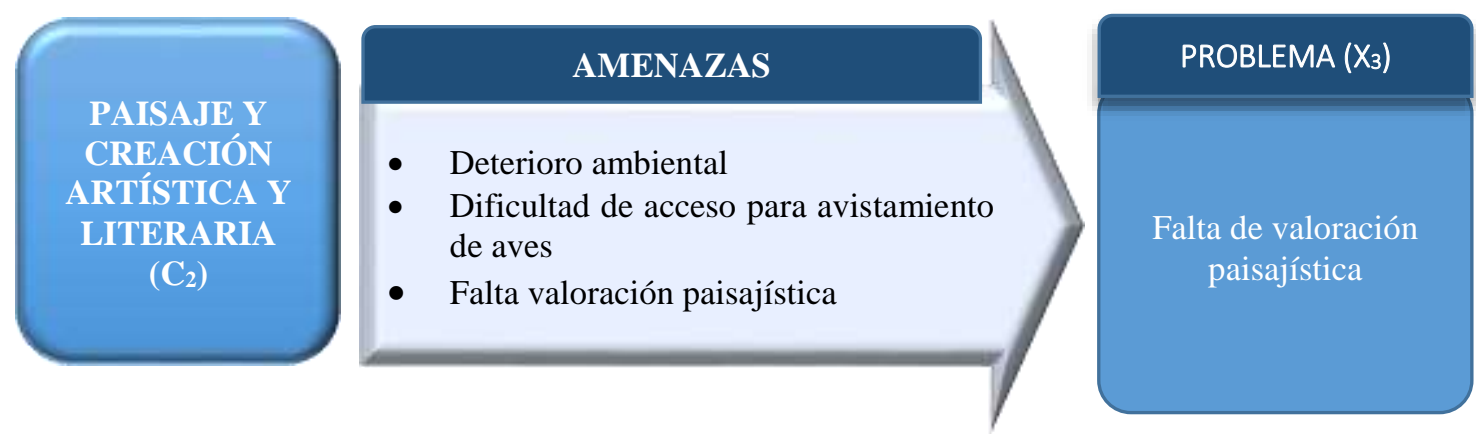

Figura 6. Identificación de amenazas y problemas para el criterio Paisaje y creación artística y literaria. Fuente: autores. 


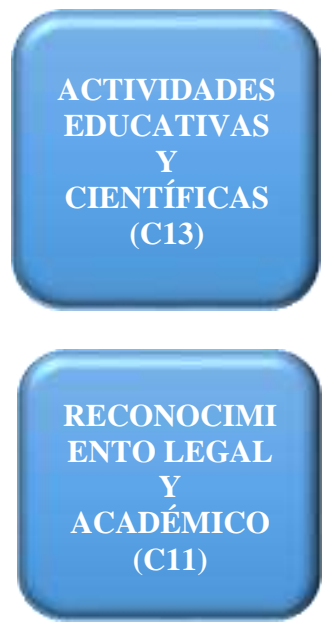

\section{AMENAZAS}

- Ausencia de procesos investigativos en la zona.

- Falta de alianzas entre agentes educativos.

- Desconocimiento de la importancia del humedal por parte de las autoridades del municipio.

- Falta de reconocimiento legal como ecosistema estratégico.

- El humedal no está incluido dentro del Plan de Ordenamiento Territorial Florencia.

\section{PROBLEMA $\left(\mathrm{X}_{4}\right)$}

\section{Falta de}

mecanismos de

ordenamiento

territorial,

investigación,

educación,

legislación y

articulación entre

comunidad e

instituciones

públicas y privadas

para la preservación

y recuperación del

humedal.

Figura 7. Identificación de amenazas y problemas para criterios de educación, actividades científicas y reconocimiento legal. Fuente: autores.

Ahora, con base en los problemas planteados (Xi) se plasmaron los objetivos para cada uno de ellos:

Tabla 7.

Planteamiento de objetivos.

\begin{tabular}{llll}
\hline Oa & OBJETIVO & Ci a Maximizar & Xi a Minimizar \\
\hline O1 & $\begin{array}{l}\text { Maximizar la dinámica ambiental del humedal Bruselas. } \\
\text { Maximizar las actividades educativas y el conocimiento de la } \\
\text { O2 }\end{array}$ & $\begin{array}{l}\text { (C18) (C26) } \\
\text { (C25) (C9) } \\
\text { importancia de la diversidad natural del humedal Bruselas y el } \\
\text { manejo de plagas y especies invasoras. }\end{array}$ & X1 \\
O3 & $\begin{array}{l}\text { Maximizar las actividades educativas respecto a la valoración } \\
\text { paisajística del humedal. } \\
\text { Maximizar las actividades educativas y científicas así como los } \\
\text { mecanismos de ordenamiento territorial, legislación y } \\
\text { reconocimiento de la importancia del humedal por parte de las } \\
\text { autoridades del municipio. }\end{array}$ & (C2) & X3 \\
O4 & & X4 (C11) \\
\hline
\end{tabular}

Con base en los objetivos, se plantean hipótesis que permitan determinar la viabilidad de alcanzar el objetivo planteado: 
Tabla 8.

Planteamiento de hipótesis para solución de problemáticas ambientales en el humedal Bruselas.

\begin{tabular}{ll}
\hline Ha & HIPOTESIS \\
\hline H1 & $\begin{array}{l}\text { Si se formula y ejecuta un plan de manejo ambiental integral, un plan de saneamiento y manejo de } \\
\text { vertimientos y se realiza la reubicación de los asentamientos subnormales entonces se maximizará la } \\
\text { dinámica ambiental del humedal Bruselas. }\end{array}$ \\
& $\begin{array}{l}\text { Si se realiza la reforestación sobre la ronda de protección y área de amortiguación del humedal, se } \\
\text { realizan procesos de educación ciudadana sobre la importancia del humedal Bruselas, sobre el manejo } \\
\text { de especies invasoras, se ejecuta un programa de seguimiento y monitoreo ambiental y se fortalecen las } \\
\text { organizaciones sociales para la gestión ambiental entonces se maximizarán las actividades educativas y } \\
\text { el conocimiento de la comunidad y las autoridades municipales respecto a la importancia de la } \\
\text { diversidad natural del humedal Bruselas y el manejo de plagas y especies invasoras. }\end{array}$ \\
& $\begin{array}{l}\text { Si se realizan procesos de educación ciudadana y se ejecutan procesos de aprovechamiento sostenible } \\
\text { de servicios ambientales entonces se maximizarán las actividades educativas respecto a la valoración }\end{array}$ \\
paisajística del humedal.
\end{tabular}

Propuesta plan de acción sobre Humedal Bruselas

A continuación, se presenta una propuesta de proyectos que pueden ser ejecutados en el humedal Bruselas de manera que se resuelvan las problemáticas presentadas en el apartado anterior.

\section{Programa: recuperación ecológica. mejora de} la dinámica ambiental del humedal Bruselas

\section{Proyectos:}

- Formulación y ejecución de plan de manejo ambiental integral del humedal Bruselas del municipio de Florencia.

- Plan de saneamiento y manejo de vertimientos de la comunidad que tiene influencia directa sobre el humedal Bruselas (mediante la construcción de la PTAR Planta de tratamiento de aguas residuales)

- Reubicación de los asentamientos subnormales que afectan la ronda hídrica del humedal Bruselas.

- Reforestación sobre la ronda de protección y área de amortiguación del humedal Bruselas.

Programa: apropiación social del humedal Bruselas como patrimonio público

\section{Proyectos:}

- Educación ciudadana sobre la importancia de la diversidad natural del humedal Bruselas.

- Educación ciudadana sobre manejo de especies invasoras.
- Educación ciudadana respecto a la valoración paisajística del humedal Bruselas.

- Aprovechamiento sostenible de servicios ambientales (agua, biodiversidad, ecoturismo) del humedal Bruselas.

\section{Programa: protección, evaluación, seguimiento y control del humedal Bruselas}

\section{Proyectos:}

- Proyecto de inclusión del humedal Bruselas en el Plan de ordenamiento territorial del municipio de Florencia.

- Programa de seguimiento y monitoreo ambiental para la conservación y preservación del humedal.

- Fortalecimiento de organizaciones sociales para la gestión ambiental del humedal Bruselas.

- Aprovechamiento sostenible de servicios ambientales (agua, biodiversidad, ecoturismo) del humedal Bruselas.

\section{Programa: generación de conocimiento}

- Creación y fortalecimientos en las IE de educación superior de una línea de investigación sobre humedales (manejo, importancia ecológica, biológica, oferta y demanda ambiental, conservación y preservación)

- Consolidación y fortalecimiento de Proyectos Ambientales Escolares -PRAESy Proyectos Ciudadanos de Educación Ambiental -PROCEDA- en torno al Humedal Bruselas. 


\section{Conclusiones}

La conservación y uso racional de los humedales es un factor fundamental, pues sus servicios ambientales son vitales para el bienestar humano; así mismo, la característica singular de los humedales conlleva al bienestar de diversidad biológica importante para el equilibrio de las especies y del ecosistema.

Cada vez que el hombre irrumpe en un ecosistema, afecta y altera su estabilidad, provocando el deterioro y la degradación de los factores que lo componen. En el municipio de Florencia esta situación no es diferente, y se evidencia en el Humedal Bruselas, en donde la intervención y asentamientos humanos desorganizados y descontrolados, han invadido sus límites y afectado de manera significativa el ecosistema.

En Florencia Caquetá el ejercicio de tipificación e inventario de humedales es incipiente. Solo se encuentran cifras oficiales de 19 humedales reconocidos en los documentos oficiales. Sin embargo, se estima que en territorio del municipio de Florencia de $2200 \mathrm{~km} 2$ y de gran influencia hídrica, se pueden registrar más humedales de los que oficialmente reportan lo estudios y los informes técnicos.

El presente estudio de identificación, localización y tipificación del humedal Bruselas, permitió evidenciar serios problemas de orden ecológico por asentamientos subnormales que generan afectación de vegetación, ocupación de cauce y de la ronda hídrica del humedal, contaminación por vertimientos de aguas residuales domésticas y hospitalarias, así como actividades de caza de fauna silvestre $y$ actividades productivas como crianza de aves de corral y actividades agrícolas sobre el área circundante del humedal.

Dadas las condiciones de deterioro del humedal Bruselas, es evidente la falta de planificación y aplicación de la normatividad existente en lo que respecta a los humedales del ámbito local, puesto que las instituciones encargadas del manejo y la gestión ambiental en el departamento, parecen ajenas o ausentes en cuanto al desarrollo de actividades y seguimiento a programas concernientes con la conservación y preservación de los humedales.

\section{Referencias}

Bravo, M., Rubiano, M., Castro, R., Luna, H., Torres, L. y Rincón, H. (2009). Plan de manejo ambiental del humedal Versalles y San Luis. Contrato de Consultoría $\mathrm{N}^{\circ} 0601$ de Corpoamazonia.

CONACyT-CONAGUA (2015). Metodología estandarizada para la evaluación de humedales en México a nivel de sitio, escala 1:20,000. Universidad Nacional Autónoma de Mexico. Recuperado de https://www.gob.mx/cms/uploads/attachment/fil e/102162/1_a_20_000.pdf

Contraloría general de la república (2012, p.26) Informe del estado de los recursos naturales y del ambiente (2012-2013). Contraloría General de la República: Bogotá, Colombia.

Corpoamazonia (2014). Caracterización biofísica o socioeconómica del área de influencia del Cerro de Miraflores y sensibilización ambiental respecto al Páramo en el departamento del Caquetá. [Mapa]. Escala 1:100.000

Declaración de Changwon (2008) Declaración sobre el bienestar humano y los humedales. Recuperado de: http://www.ramsar.org/sites/default/files/docum ents/pdf/cop10/cop10_changwon_spanish.pdf Márquez, G. (1997). Ecosistemas como Factores de Bienestar y Desarrollo. Ensayos de Economía. Universidad Nacional de Colombia. Sede Medellín. Facultad de ciencias humanas y departamento de economía, 13(7), p. 113-141.

Minambiente y Desarrollo sostenible. (2014). V Informe nacional de Biodiversidad de Colombia. Ante el convenio de diversidad biológica. Disponible en: http://www.co.undp.org/content/dam/colombia/ docs/MedioAmbiente/undp-coinformebiodiversidad-2014.pdf

Ministerio de Medio ambiente (2002). Política Nacional para humedales interiores de Colombia. Estrategias para su conservación y uso sostenible. Panamericana Formas e impresos: Bogotá, Colombia. Disponible en: https://www.minambiente.gov.co/images/Bosqu esBiodiversidadyServiciosEcosistemicos/pdf/N ormativa/Politicas/polit_nal_humedales_int_col ombia.pdf

Olaya, A. y Sánchez, R. (2003) Ecosistemas estratégicos del Huila. Significado ecológico y sociocultural. Universidad Surcolombiana.

Ramsar (2005). Estrategia Regional de Conservación y Uso sostenible de los Humedales Altoandinos, proyección 2005-2015. Novena reunión delas partes contratantes en la convención sobre los humedales. Disponible en: http://www.condesan.org/docinfonotas/ramsar\% 202.pdf

Ramsar (2015). Nota informativa 7. Estado de los humedales del mundo y de los servicios que prestan a las personas: una recopilación de análisis recientes. Dsiponible en: 
http://www.ramsar.org/sites/default/files/docum ents/library/cop12_doc23_bn7_sowws_s.pdf

Ricaurte, L.F., Núñez-Avellaneda, M., Marín, C.A., Velásquez-Valencia, A., Pinilla, M.C., Betancourt, B. Salazar, C. Mojica, J. I. (2014). Inventario y tipificación de humedales en la cuenca del río Orteguaza. Instituto Amazónico de Investigaciones Científicas Sinchi, Convención de Ramsar. Bogotá, Colombia.

Secretaría de la Convención de Ramsar (2010). Inventario de humedales: Marco de Ramsar para el inventario y la descripción de las características ecológicas de los humedales.
Manuales Ramsar para el uso racional de los humedales, $4^{\mathrm{a}}$ edición, vol. 15. Secretaría de la Convención de Ramsar, Gland (Suiza).

Secretaría de la Convención de Ramsar. (2010. Uso racional de los humedales: Conceptos y enfoques para el uso racional de los humedales. Manuales Ramsar para el uso racional de los humedales, $4^{\text {a }}$ edición, vol. 1. Secretaría de la Convención de Ramsar, Gland (Suiza).

Vergel, J. Losada, S. y Montoya, L. (2009). Inventario y caracterización de los humedales urbanos del municipio de Florencia. Alcaldía de Florencia - Corpoamazonia. 